\title{
Pembuatan Augmented Reality Sebagai Media Pembelajaran Tentang Pahlawan Nasional
}

\author{
Yudha Pradana ${ }^{a}$ Ahmad Rizki Aditya ${ }^{b}$ \\ ${ }^{a, b}$ Politeknik Negeri Media Kreatif
}

INFORMASI ARTIKEL

Sejarah Artikel:

Diterima Redaksi: 18 Mei 2020

Diterbitkan Online : 31 Juli 2020

KATA KUNCI

Augmented Reality

Media Pembelajaran

Pahlawan Nasional

KORESPONDENSI

Email : yudha.pradana@gmail.com

\section{A B S T T R A C T}

Perkembangan teknologi dapat sejalan dengan penggunaan media pembelajaran. Salah satu hasil dari perkembangan teknologi ialah augmented reality. Augmented reality sebagai media pembelajaran dinilai akan memberikan nilai lebih terhadap pembelajaran karena bersifat interaktif dan menggabungkan dunia nyata dengan dunia maya. Pembuatan augmented reality ini dilakukan dalam materi pahlawan nasional yang sudah ditetapkan yakni Soekarno, Mohammad Hatta, Pattimura, Ki Hajar Dewantara, dan Soedirman. Rumusan masalah yang ditetapkan ialah bagaimana pembuatan augmented reality sebagai media pembelajaran pada materi pahlawan nasional. Tujuan penulisan ialah untuk mengetahui pembuatan augmented reality sebagai media pembelajaran pada materi pahlawan nasional. Tahapan pembuatan yang dilakukan ialah melalui tahap praproduksi, tahap produksi, dan tahap pascaproduksi. Simpulan yang ditemukan ialah pembuatan augmented reality ini dapat membantu guru dan siswa dalam pembelajaran sehingga pembelajaran lebih bermakna.

\section{PENDAHULUAN}

Pengunaan media dalam pembelajaran tentu memiliki peranan penting sebagai alat bantu atau pengantar materi yang diberikan sehingga akan memudahkan berlangsungnya pembelajaran. Namun masih banyaknya keterbatasan dalam penggunaan media pembelajaran seperti keterbatasan kemampuan dalam menggunakan media pembelajaran atau terbatasnya media pembelajaran alternatif yang digunakan oleh guru sehingga pembelajaran hanya menggunakan media buku ajar.

Perkembangan teknologi dapat bersinergis dengan pembelajaran melalui pemanfaatannya agar pembelajaran dapat lebih mudah dan bermakna. Beberapa manfaat media pembelajaran menurut Sudjana dan Rivai (2005) diantaranya ialah :

1. Pembelajaran akan lebih menarik perhatian siswa sehingga dapat menumbuhkan motivasi belajar siswa.

2. Bahan pembelajaran akan lebih jelas maknanya sehingga dapat lebih dipahami oleh para siswa, dan memungkinkan siswa menguasai tujuan pembelajaran lebih baik.
3. Metode mengajar akan lebih bervariasi, tidak sematamata komunikasi verbal melalui penuturan kata-kata oleh guru, sehingga siswa tidak bosan dan guru tidak kehabisan tenaga, apalagi bila guru mengajar untuk setiap jam pelajaran.

4. Siswa lebih banyak melakukan kegiatan belajar, sebab tidak hanya mendengarkan uraian guru, tetapi juga aktivitas lain seperti mengamati, melakukan, mendemonstrasikan dan lain-lain.

Penulisan rujukan dilakukan dengan menuliskan nomor referensi dalam kurung $[1,2]$. Penulisan referensi diawal kalimat juga sama. Jurnal Online Multimedia sangat menyarankan untuk memakai aplikasi bantu referensi seperti Mendeley atau EndNote. Mendeley lebih disukai karena tidak memerlukan biaya tambahan untuk lisensi aplikasi.

\section{TINJAUAN PUSTAKA}

Ragam media pembelajaran yang dapat digunakan oleh pengajar mengutip Leshin, Pollock dan Reigeluth (Arsyad, 2006) sebagai berikut: 
1. Berbasis manusia; guru, instruktur, tutor, main-peran, kegiatan kelompok, field-trip.

2. Berbasis cetak; buku, penuntun, buku latihan, alat bantu kerja, lembaran lepas.

3. Berbasis visual; buku, bagan, grafik, gambar, peta, transparasi, slide.

4. Berbasis audio-visual; video, film, program slide-tape, televisi.

5. Berbasis komputer; pengajaran dengan bantuan komputer, interaktif video, hypertext.

Salah satu media yang muncul sejalan dengan perkembangan teknologi adalah augmented reality. Manuri dan Sanna (2016) mengatakan bahwa augmented reality merupakan salah satu bagian dari virtual environment yang memberikan gambaran kepada pengguna tentang penggabungan dunia nyata dengan dunia maya dilihat dari tempat yang sama dan memiliki tiga karakteristik, yaitu bersifat interaktif, menurut waktu nyata, dan berbentuk tiga dimensi. Raajan (2014) mengemukakan bahwa augmented reality pertama kali digunakan pada tahun 1957-1962 oleh Norton Heilig berupa sebuah simulator yang diberi nama sensorama yang dapat mensimulasikan visual, getaran, dan bau.

Keterkaitan penggunaan augmented reality sebagai media pembelajaran telah diketahui hasilnya secara empirik. Ilmawan Mustaqim (2016) menyimpulkan kegunaan penggunaan augmented reality sebagai media pembelajaran yang interaktif dan nyata serta secara langsung oleh peserta didik, meningkatkan minat peserta didik karena dapat meningkatkan imajinasi peserta didik dengan dunia nyata secara langsung, merangsang pola pikir peserta didik dalam berpikir kritis terhadap sesuatu masalah dan kejadian yang ada pada keseharian, memberikan pembelajaran dimanapun dan kapanpun peserta didik, memvisualisasikan konsep abstrak untuk pemahaman dan struktur suatu model objek.

Ilmawan Mustaqim dan Nanang Kurniawan (2017) menyimpulkan melalui penggunaan augmented reality sebagai media pembelajaran ialah guru dapat membuat media pembelajaran yang menyenangkan, interaktif, dan mudah digunakan, serta dapat menggantikan modul pembelajaran yang belum ada di sekolah dalam bentuk virtual atau maya.

Melalui pemaparan di atas, penulis tertarik untuk membuat augmented reality sebagai media pembelajaran. Dalam riset ini penulis mengidentifikasi kebutuhan dan menetapkan bahwa augmented reality yang akan dibuat ialah berhubungan dengan pembelajaran Ilmu Pengetahuan Sosial di Sekolah Dasar. Penulis juga mengidentifikasi salah satu objek dalam riset ini yakni SDN Anyelir 1 Depok dimana pembelajaran masih menggunakan media buku ajar dan minat belajar yang masih rendah.

Rumusan masalah yang ditetapkan ialah bagaimana pembuatan augmented reality sebagai media pembelajaran pada materi pahlawan nasional?. Tujuan penulisan ialah untuk mengetahui pembuatan augmented reality sebagai media pembelajaran pada materi pahlawan nasional.

Batasan dalam pembuatan karya ini ialah:

1. Konten augmented reality ini berisi tentang bagaimana mevisualisasikan object pahlawan tersebut ke dalam bentuk augmented reaility.
2. Augmented reality ini menggunakan software khusus untuk proses pengerjaannya seperti adobe illustrator, adobe photoshop, cinema 4D, vuforia, dan unity.

3. Objek 3D Augmented Reality yang digunakan merupakan representasi dari ilustrasi yang ada pada kartu tersebut.

4. Penulis membuat lima Pahlawan yang ada dalam buku pelajaran kelas empat dan lima sekolah dasar yaitu Ir.Soekarno, Drs. Moh. Hatta. Ki Hajar Dewantara, Pattimura, dan Jendral Soedirman.

\section{HASIL DAN PEMBAHASAN}

Sebelum membuat aplikasi augmented reality, penulis menganalisis kompetensi pembelajaran yang harus dicapai oleh siswa dan mengelaborasi pembelajaran yang selama ini dilakukan. Analisa mengenai kebutuhan fungsional dan non-fungsional juga dilakukan agar pembuatan augmented reality ini dapat berjalan dengan tepat sesuai sasaran dan target yang sudah dicanangkan.

Kebutuhan fungsional merupakan kebutuhan yang berisi proses-proses apa saja yang ada atau disediakan. Berikut adalah kebutuhan fungsional yang ada pada aplikasi ini :

1. Menampilkan tampilan tiga dimensi berupa pahlawan.

2. Terdapat button informasi mengenai pahlawan.

3. Objek tiga dimensi pahlawan dapat diputar menggunakan touchscreen

4. Terdapat petunjuk penggunaan aplikasi.

Sedangkan kebutuhan non-fungsional merupakan kebutuhan yang meitikberatkan pada perlengkapan yang digunakan untuk menunjang pembuatan karya tugas akhir ini. Adapun kebutuhan yang digunakan untuk menunjang pembuatan karya tugas akhir ini dibagi menjadi dua, yaitu hardware dan software. Kebutuhan hardware ialah laptop dengan spesifikasi Processor Name $2.8 \mathrm{GHz}$ Intel Core ${ }^{\mathrm{TM}}$ i7, Chipset Intel HD Graphic 630, RAM 16 GB, sistem opersional Windows 10 Pro 64-bit (10.0, Build 17134), smartphone android, dan Pen Tablet Wacom Intuos Comic CTH90. Sedangkan kebutuhan software ialah Adobe Photoshop CS6, Adobe Illustrator CS6, Cinema 4D R18, Vuforia, dan Unity 3D

Setelah itu ditentukan tahap pembuatan augmented reality. Pembuatan augmented reality ini melalui tiga tahapan yakni tahap praproduksi, tahap produksi, dan tahap pascaproduksi. Tahap praproduksi merupakan tahap awal pembuatan dimana penulis melakukan curah pendapat dengan berbagai pihak terkait mengenai rancangan karya dan identifikasi kebutuhan yang diperlukan termasuk pengumpulan data yang berhubungan dengan aplikasi yang akan dibuat. Pengumpulan data dilakukan melalui studi kepustakaan dan wawancara. Studi kepustakaan dilakukan untuk mendapatkan berbagai literatur yang dibutuhkan terkait dengan konsep pahlawan nasional dan konsep teknis mengenai augmented reality dan perangkat lunak yang akan digunakan.

Dalam tahap praproduksi disepakati bahwa augmented reality ini akan menampilkan pahlawan nasional Soekarno, Mohammad Hatta, Pattimura, Ki Hajar Dewantara, dan Soedirman. Selain itu muatan dalam augmented reality pahlawan nasional ialah berupa biografi singkat dan nilai kepahlawanan tokoh-tokoh tersebut. 
Melalui tahap praproduksi juga disepakati bahwa desain augmented reality secara pewarnaan menggunakan warna yang umumnya sesuai dengan warna-warna atribut pakaian, warna kulit pahlawan dan sedikit warna aktif. Tipografi yang dipilih ialah menggunakan Lucida Bright karena terlihat jelas dan tegas sesuai dengan karakteristik pahlawan dan digunakan untuk logo aplikasi, heading poster dan heading main menu aplikasi serta Myriad Pro karena terlihat sederhana, tenang dan tegas namun memiliki keterbacaan yang jelas dab digunakan untuk main menu, menu informasi dan penjelasan pada poster dan aplikasi.

Tahap produksi yang dilakukan meliputi kegiatan pembuatan asset karya dan kegiatan menganimasikan karya mencakup modelling $3 \mathrm{D}$, texturing, rigging, dan animating. Selanjutnya dalam tahap produksi dilakukan pembuatan user interface dan build aplikasi untuk digunakan dalam perangkat smartphone dengan sistem operasi android yang dilanjutkan dengan pembuatan marker untuk menampilkan augmented reality.

Modelling 3D merupakan proses pembuatan objek 3D pahlawan dimana yang akan menjadi objek utama pembuatan augmented reality ini.

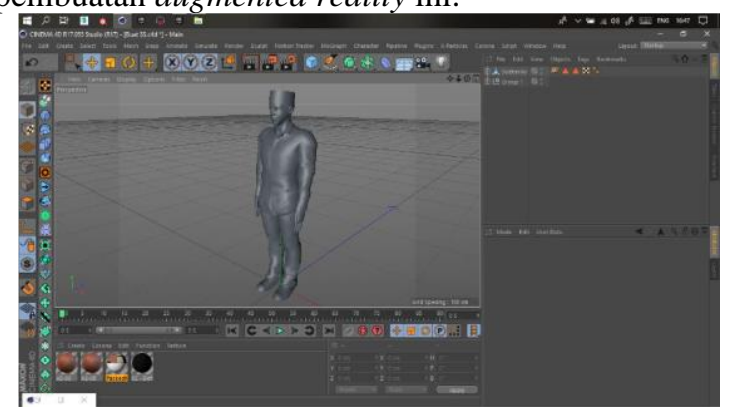

Gambar 1 Modelling Objek

Sumber: penulis

Texturing merupakan proses pemberian karakteristik pada permukaan objek seperti warna dan highlight lainnya yang telah dibuat dengan UV mapping menggunakan adobe photoshop sebagai proses pemetaan permukaan objek 3D yang dipresentasikan menjadi gambar 2D.

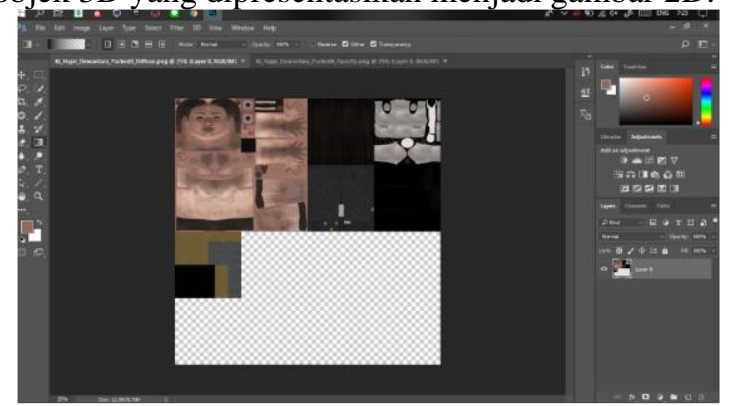

Gambar 2 Texturing Objek

Sumber: penulis

Rigging adalah proses pemberian tulang pada objek 3D yang terdiri dari beberapa tulang yang saling berhubungan. Tahap ini berguna untuk membuat animasi pada objek 3D yang akan dianimasikan.

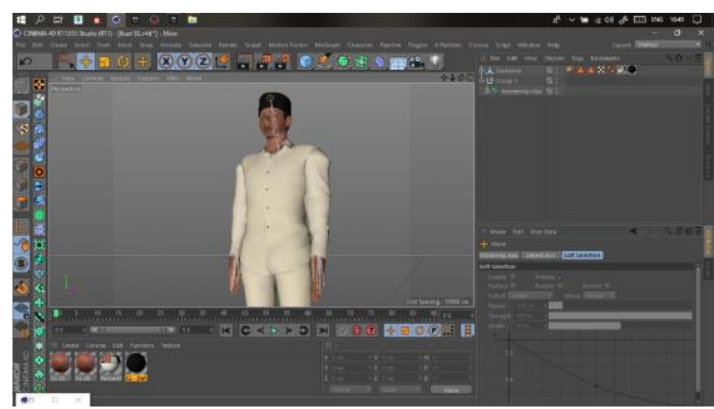

Gambar 3 Rigging Objek

Sumber: penulis

Animating merupakan proses memberikan gerakan atau animasi pada objek 3D. Animating dilakukan dengan hanya menggerakan tulang objek 3D pahlawan, namun posisi pahlawan tetap di tempat.

User interface dirancang dengan menampilkan splash screen, about screen, information screen, dan juga pembuatan button pada aplikasi.

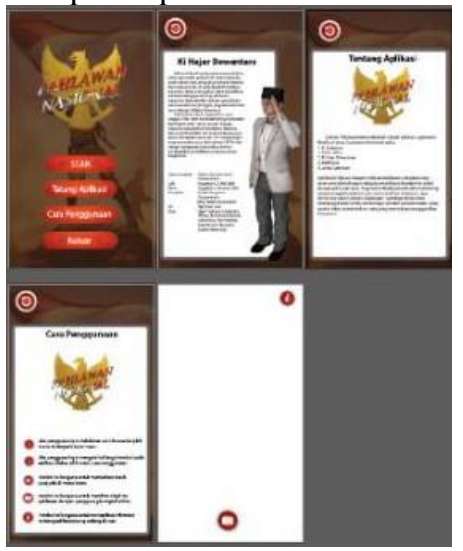

Gambar 4 Rancangan User Interface Sumber: penulis

Build aplikasi telah dibuat menggunakan unity 3D dibuild menjadi file APK yang nantinya file siap untuk diajalankan pada smartphone android. Pembuatan aplikasi yang dilakukan ialah dengan membuat database, target image dan lisence key aplikasi menggunakan vuvoria sebagai library marker. Selanjutnya pembuatan aplikasi dimulai dengan new project.

Marker dibuat sebagai penampil augmented reality yang akan di-scan untuk memunculkan objek 3D. Pembuatan marker menggunakan software adobe illustrator CS 6.

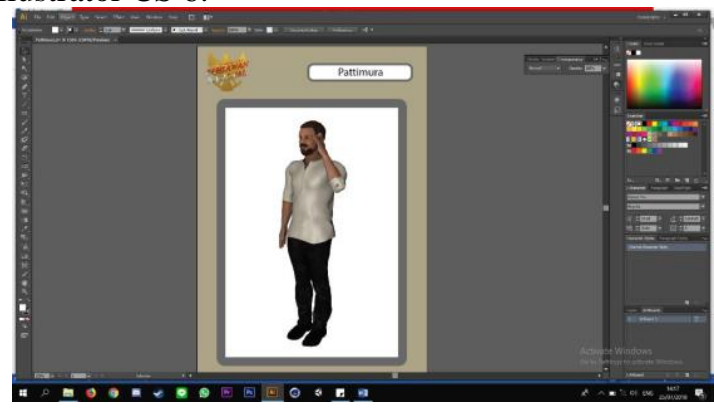

Gambar 5 Pembuatan Marker

Sumber: penulis 
Tahap terakhir ialah pascaproduksi dengan melakukan testing aplikasi dan publish aplikasi. Testing dilakukan untukmmembandingkan kualitas dan start up aplikasi. Aplikasi ini di test pada dua smartphone android dengan tipe Redmi 5 yang memiliki sistem operasi Marshmallow dengan spesifikasi RAM 3GB, CPU Quadcore Max $1.80 \mathrm{GHz}$ dengan keterbacaan aplikasi dapat dibuka dalam durasi waktu tiga detik dan tipe Redmi 4x yang memiliki sistem operasi Nougat dengan spesifikasi RAM 2GB, CPU Octa-core Max $1.40 \mathrm{GHz}$ dengan keterbacaan aplikasi dapat dibuka enam detik. Kesimpulan testing yang dilakukan ialah sistem operasi android tidak terlalu mempengaruhi kinerja pada aplikasi, tapi spesifikasi perangkat yang digunakan mempengaruhi kinerja dari aplikasi tersebut, sehingga aplikasi ini dapat digunakan secara baik.

Selain menguji perangkat, testing dilakukan untuk mengetahui usability oleh pengguna yang diberikan pada guru dan siswa. Hasilnya penggunaan aplikasi ini tidak terlalu rumit dan dapat dikatakan mempermudah bagi pembelajaran.

\section{PENUTUP}

\section{Kesimpulan}

Augmented reality ini dibuat sebagai media pembelajaran yang diharapkan akan memudahkan dan mendukung proses pembelajaran dengan pemilihan tema pahlawan nasional. Pembuatan augmented reality ini terdiri dari tahap praproduksi berupa curah pendapat dan pengumpulan data, tahap produksi yang meliputi perancangan objek secara modelling, texturing, rigging, rendering, animating, pembuatan desain user interface dan marker, pembuatan dan build aplikasi, serta tahap pascaproduksi berupa testing dan publish aplikasi.

\section{Saran}

Penggunaan media pembelajaran yang variatif dan interaktif diperlukan dalam sebuah pembelajaran. Oleh karenanya penulis menyarankan pengembangan aplikasi yang sudah dibuat dari segi konten dan animasi objek 3D agar lebih menarik lagi. Selain itu dapat dimungkinkan juga aplikasi ini dikembangkan dalam bentuk markerless.

\section{DAFTAR PUSTAKA}

Arsyad, A. 2006. Media Pembelajaran. Jakarta: Raja Grafindo Persada.

Manuri, F., dan Sanna, A. 2016. A Survey on Applications of Augmented Reality. Advances in Computer Science: An International Journal, 18-27.

Mustaqim, I. 2016. Pemanfaatan Augmented Reality sebagai Media Pembelajaran. Jurnal Pendidikan Teknologi dan Kejuruan, Vol.13, No.2, 174-183.

Mustaqim, I. dan Nanang Kurniawan. 2017. Pengembangan Media Pembelajaran Berbasis Augmented Reality. Jurnal Edukasi Elektro, Vol. 1, No. 1, 36-48.

N.R Raajan. et al. 2014. A Review on: Augmented Reality Technologies, System and Applications. Jurnal Asian Network for Scientific Information. 14 (14), 1485-1486.
Sudjana, N dan Ahmad Rivai. 2005. Media Pengajaran. Bandung: Sinar Baru Algensindo 